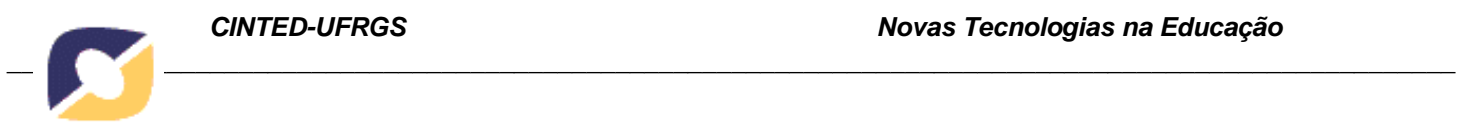

\title{
Cultura Digital e Aprendizagem Cooperativa
}

Aline Silva De Bona - vivaexatas@yahoo.com.br Anuar Daian de Morais - anuar_com_u@yahoo.com.br Marcus Vinicius de Azevedo Basso - mbasso@ufrgs.br

Léa da Cruz Fagundes - leafagun@ufrgs.br

Resumo: O trabalho é uma pesquisa bibliográfica de conceitos importantes para a área da Informática na Educação como: redes, ciberespaço, cibercultura, interação e aprendizagem cooperativa na cultura digital. A base teórica para aprendizagem está alicerçada nos conceitos de colaboração e cooperação dos Estudos Sociológicos de Jean Piaget de 1973, e tais conceitos são conectados e elucidados com duas pesquisas na área da Educação Matemática: os Portfólios de Matemática e o Espaço de Aprendizagem Digital da Matemática, realizada por um dos autores. O objetivo deste é proporcionar um momento de reflexão, a partir de resultados obtidos nas duas pesquisas supracitadas que articulam prática e teoria, aos professores e pesquisadores da área, sobre tais conceitos, valendo-se da necessidade de se escutar os estudantes para assim contribuir para a melhoria da educação no Brasil. Nesta pesquisas verifica-se a construção dos conceitos de matemática pelos estudantes da escola básica, sendo um resultado positivo da articulação destes conceitos discutidos no artigo.

Palavras- Chaves: Cibercultura, Cultura Digital, Aprendizagem Cooperativa, Interação, Colaboração.

\section{Digital Culture and Learning Cooperative}

Abstract: The work is a bibliographic research of important concepts for the area of Computing in Education as networks, cyberspace, cyberculture, interaction and cooperative learning in the digital culture. The theoretical basis for learning is based on the concepts of collaboration and cooperation of Sociological Studies of Jean Piaget, 1973, and such concepts are elucidated with two connected and research in Mathematics Education: Portfolios of the Mathematics and Space Digital Learning of Mathematics, performed by one of the authors. The objective is to provide a moment of reflection, the results from both surveys supracidas that link theory and practice, teachers and researchers on these concepts, using the need to listen to the students so as to contribute to improving education in Brazil. In this research there is the construction of math concepts by elementary school students, a positive result of the articulation of the concepts discussed.

Key-words: Cyberculture, Digital Culture, Cooperative Learning, Interaction, Collaboration.

\section{Introdução}




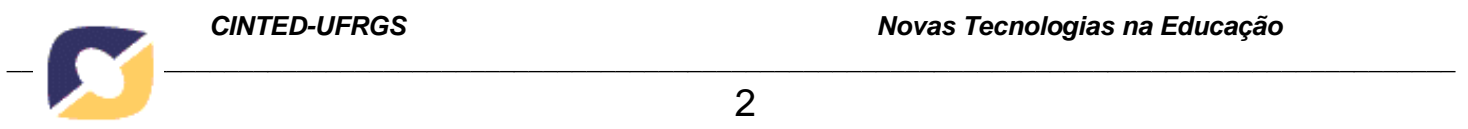

Há muitas pesquisas na área da Informática na Educação que são importantes para a mudança de paradigma social e educacional, no entanto se faz necessário refletir sobre quais conceitos estamos nos apropriando para desenvolver uma ação, seja ela como professor e/ou pesquisador e/ou estudante- pesquisador.

No âmbito da educação matemática o baixo desempenho dos estudantes nas avaliações externas (seja na educação básica ou superior) estão sempre sendo alvo de atenção na mídia pelo baixo desempenho dos estudantes no Brasil. Além disso, segundo Morin (2000), vive-se num mundo complexo e sob um paradigma ainda mais complexo no que se refere particularmente a educação. Desta forma, é importante se pesquisar constantemente o contexto da escola e, em função disso, surge a finalidade deste artigo, que é uma pesquisa bibliográfica sobre os conceitos de redes, ciberespaço, cibercultura, interação e aprendizagem cooperativa na cultura digital. Além disso, a reflexão apresentada neste trabalho, baseia-se em pesquisas que incorporam tais conceituações no processo de aprender a aprender matemática e que apresentaram resultados de efetiva aprendizagem de conceitos de matemática.

Com isso, o objetivo do artigo é apontar discussões teóricas sobre metodologias possíveis de serem adotadas em sala de aula e que proporcionam aos estudantes uma curiosidade de aprender a aprender e a aprender a pensar matemática (ou outra área do conhecimento), sob uma visão construtivista piagetiana do processo de aprendizagem online de um estudante imerso na cultura digital. Para isso articula-se a "antiga" teoria dos estudos sociológicos de Piaget de 1973 com as recentes conceituações de cultura digital.

Paralelamente, o artigo discute teoricamente a interação como um conceito central para a área da Informática, Informática na Educação, Educação e Educação Matemática, que dá suporte à crescente apropriação das tecnologias digitais em rede pelos estudantes na escola. $\mathrm{O}$ artigo está organizado em quatro secções, sendo a primeira a introdução; na segunda apresenta-se uma discussão sobre redes, ciberespaço $e$ a cibercultura; na terceira há uma reflexão sobre interação e aprendizagem cooperativa na cultura digital para a educação matemática, sob uma perspectiva piagetiana. e, por fim, as considerações finais.

\section{Redes, Ciberespaço e cibercultura}

Já faz tempo que as redes influenciam a nossa cultura. Se refletirmos um pouco sobre o assunto, veremos que nosso cotidiano é suprido por um grande número de redes de serviços, tais como: o abastecimento de água e esgoto, de energia elétrica, meios de transporte e comunicação. Todas essas redes são reais e influenciam nossa forma de comunicar, de pensar e de produzir significados.

Sendo assim, para Parente (2004) antes mesmo do surgimento do chamado Ciberespaço, as redes já influenciavam a forma como o indivíduo se relaciona com o mundo social, dando significado às crenças e valores compartilhados em tal dimensão, e que irão constituir a experiência histórica e coletiva dos grupos e populações. Segundo 


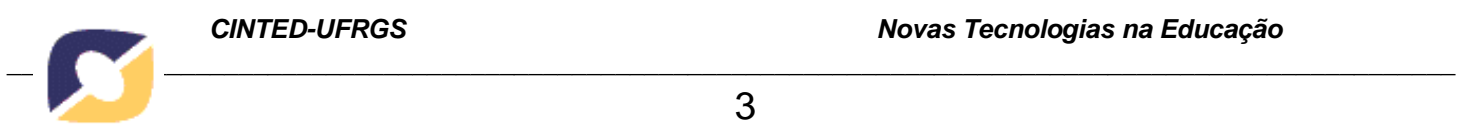

esse autor, no momento em que as Novas Tecnologias Digitais (NTD) - contempla as tecnologias de informação e comunicação em rede ou não, segundo Arruda (2004) passaram a ter um papel estruturante na nova Ordem Mundial, nada escapa à rede, tudo é definido a partir dela: a sociedade, o capital, o mercado, o trabalho, a arte, a guerra, etc.

Para Pierre Lévy a rede formada pelas NTDs é o chamado Ciberespaço, segundo ele: Ciberespaço é o novo meio de comunicação que surge da interconexão mundial de computadores, o termo específica não apenas a infraestrutura material da comunicação digital mas também o universo oceânico de informações que ela abriga, assim como os seres humanos que navegam e alimentam esse universo. (1999, p. 17).

Além disso, um dos traços mais marcantes do ciberespaço é que, através de sua virtualidade, ele se constitui num espaço que está em todo lugar e em lugar nenhum. Nele a informação pode ser acessada por qualquer pessoa e de qualquer lugar. Além disso qualquer usuário pode incluir novas informações ao ciberespaço, sendo assim ele constitui um espaço livre, informal e descentrado. Tais características garantem recursos para a produção de conhecimento por parte de seus usuários.

Dessa forma, acompanhamos o surgimento de uma nova cultura a cultura digital ou cibercultura que segundo Lévy é "o conjunto de técnicas (materiais e intelectuais), de práticas, de atitudes, de modos de pensamento e de valores que se desenvolvem juntamente com o crescimento do ciberespaço" (1999, p.17). Na cultura digital, as trocas entre os sujeitos são fundamentais para a existência e manutenção da própria rede, onde a interação entre as pessoas é mediada por diferentes recursos tecnológicos, que também interagem entre si.

Sendo assim, a interação social é potencializada pelo uso das NTDs e, consequentemente, a socialização é uma característica intrínseca à cultura digital. Importante pontuar que a cibercultura, historicamente, é uma sintetização da relação da sociedade com as tecnologias digitais da informação e da comunicação. Segundo Lemos (2002), com a evolução das tecnologias digitais a ideia da cultura digital se sobrepõe, porque a cibercultura é a cultura em rede, é o impacto das NTDs e da conexão em rede da sociedade, além de ser um elemento do paradigma da complexidade, para Morin (2000) e da manifestação cultural da matemática, para D’Ambrozio (1999).

Em função dessa nova forma de se organizar, pensamos que a cultura escolar também deve se transformar, abandonando assim o modelo de cultura industrial, para um modelo mais dinâmico, interativo e adequado à cibercultura. Mas qual seria tal modelo?

Avaliamos que a concepção educacional construtivista atende à essas necessidades. Para Piaget a interação social é indispensável para que a criança desenvolva uma lógica, visto que "A criança procura evitar contradizer-se em presença de outras pessoas” (Piaget apud Kamii, 1986, p. 51). Além disso, é a partir da interação social que qualquer pessoa entra em contato com diferentes pontos de vista que podem gerar o que Piaget chamou de Conflito Cognitivo. 


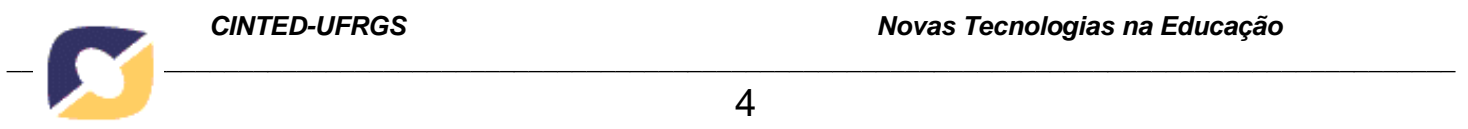

Além disso, nos Estudos Sociológicos (1973) Piaget explica que interação é a ação que modifica outras ações e que pode ser de dois tipos: a interação do sujeito com o objeto, e/ou do sujeito com outro sujeito. Na ideia de ação para Piaget (1973) está implícito uma forma de conhecimento autônomo do individuo, que, a partir do terceiro estádio de desenvolvimento, esta ação interiorizada e reversível se denomina operação. Estes dois elementos que caracterizam a operação pode ser explicado assim: interiorizar é a ideia de que esta ação foi definida a partir de outra, enquanto que reversível é uma ação que anula a anterior através de um conjunto de novos esquemas de ações coordenados e organizados entre si, uma estrutura.

Inserindo-se a concepção construtivista de Piaget na educação que, no nosso entendimento, contempla a cultura digital, se faz necessário entender e diferenciar que a interação não é apenas uma forma de comunicação (como é usual em artigos, textos e pesquisas na área da Informática), mas é uma ação fundamental ao processo de aprendizagem do indivíduo inserido naturalmente na cultura digital por sua participação em diversas redes, sejam elas de jogos, sociais e outras.

Portanto, é o contexto social que incentiva o sujeito a pensar sobre os outros pontos de vista em relação ao seu próprio, constituindo-se num processo de descentração que é fundamental para o desenvolvimento lógico-matemático, moral e social. Nessa perspectiva o conhecimento não é algo fixo e acabado, ele surge de um contexto de trocas e de um processo de reflexões sobre aquilo que se conhece e o que se quer conhecer. E nesse contexto de cultura digital o processo de aprendizagem pode ser potencializado, já que em ambas a interação é sua principal característica. Novamente cita-se Piaget (1973) que aponta as duas formas de aprender que é por colaboração e por cooperação, sendo a segunda mais complexa que a primeira. Tais conceituações são discutida na seção 3 .

Sendo assim, o uso das NTDs propõe a inclusão da escola na cultura digital. Para Fagundes "estamos vivendo um processo de rápidas transformações nas formas de ser, viver, relacionar-se. (...) Torna-se quase impossível planejar e definir com antecedência o que deve ser aprendido e que competências são necessárias para habitar esse "mundo novo" (1999, p. 13). E existe cada vez mais a necessidade deste novo paradigma educacional ser incorporado pelos professores em sala de aula para que os estudantes sintam-se mobilizados a aprender a aprender, segundo Bona (2010).

\section{Interação e Aprendizagem Cooperativa para Piaget na cultura digital para a Educação Matemática}

Em Piaget (1973), as interações são definidas como sendo ações se modificando umas as outras, conforme determinadas leis de organização ou de equilíbrio, e podem ser de dois tipos como dito anteriormente. Há a interação entre o sujeito e os objetos e a interação entre o sujeito e outros sujeitos. É desse modo que a relação entre o sujeito e o objeto modifica o sujeito e o objeto ao mesmo tempo, porque ocorre assimilação de um ao outro e a acomodação do sujeito ao objeto. Esse processo acontece em todo trabalho 


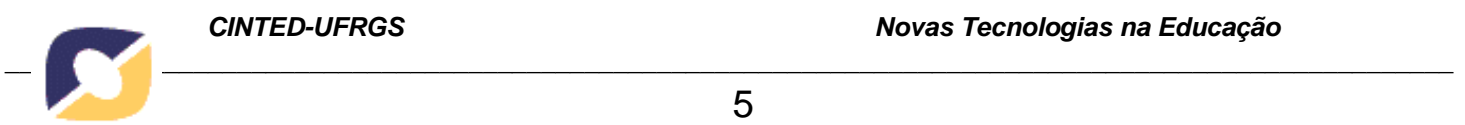

coletivo humano, pois cada relação social constitui uma totalidade nela mesma, capaz de criar características novas que transformam o indivíduo em sua estrutura mental.

A partir da interação entre pelo menos dois indivíduos surge uma totalidade que é constituída pelo conjunto das relações interindividuais de uma mesma sociedade. Esta totalidade não constitui a soma dos indivíduos, nem a soma de uma realidade superposta aos indivíduos, mas a de um sistema de interações que modifica os sujeitos em sua própria estrutura.

O conhecimento humano é essencialmente coletivo, e a vida social constitui um dos fatores essenciais da formação e do crescimento dos conhecimentos pré-científicos e científicos. Tais conhecimentos não partem nem do sujeito nem do objeto, mas da interação indissociável entre eles, para avançar a partir deste ponto na dupla direção de uma exteriorização objetivante e de uma interiorização reflexiva.

$\mathrm{Na}$ evolução cognitiva do sujeito existem patamares sucessivos de estruturação lógica ou de inteligência prática, intuitiva ou operatória. Cada um desses patamares é caracterizado por um determinado tipo de cooperação ou de interação social. As interações são constituídas por ações, e a cooperação consiste em um sistema de operações, de tal modo que as atividades do sujeito se exercendo sobre os objetos, e as atividades do sujeito agindo sobre outros sujeitos se reduzem, na realidade, a um único sistema de conjunto, no qual o aspecto social e o aspecto lógico são indissociáveis, tanto na forma como no conteúdo.

Assim, “[...] cooperar na ação é operar em comum, isto é, ajustar por meio de novas operações (qualitativas ou métricas) de correspondências, reciprocidade ou complementaridade, as operações executadas por cada um dos parceiros" (Piaget, 1973, p.105). Enquanto que "colaborar resume-se à reunião das ações que são realizadas isoladamente pelos parceiros, mesmo quando o fazem na direção de um objetivo" (1973, p. 81). Um exemplo de colaboração é quando, ao resolverem uma série de desafios apresentados pelo professor, dois estudantes decidem se organizar da seguinte maneira: cada um resolve um determinado número de desafios de forma isolada, sem a participação na resolução do outro. Neste caso há uma reunião de ações que tem o mesmo objetivo, resolver os desafios propostos pelo professor.

Já na cooperação há necessidade de pensar junto, resolver conjuntamente. $\mathrm{O}$ termo ajustar utilizado por Piaget é essencial para diferenciar cooperação de colaboração, porque quando as ações dos estudantes são ajustadas umas as outras, partese do que já foi realizado pelo colega, por meio da aceitação ou refutação da ação alheia. Essa integração ou negação ocorre mediante ação de cooperação.

Por exemplo, na resolução de um exercício em conjunto, com três estudantes, denominados por A, B e C, cada colega pensa no que o outro colega realizou e ao pensar deve apresentar argumentos ao aceitar ou refutar, ou seja, ao ajustar suas resoluções estes estudantes operam conjuntamente, e estão cooperando. Ainda cita-se um exemplo para ilustrar as ações de cooperação dos estudantes na resolução de um problema de matemática, em que um estudante parte da ideia do colega para seguir 
resolvendo, assim concorda com o raciocínio dos (ou do) colegas: Estudante A: "acho que para resolver o problema equacionei: $x+y=9$ e $2 x-y=3$, ne?"; Estudante B: "concordo...mas fiz assim na segunda $y=2 x$-3....", Estudante A: "ok, é o mesmo....só resolver agora....", Estudante C: "vamos fazer por adição pois y igual quantidade $e$ sinais opostos.....", Estudante A: " seguindo tua ideia C temos $3 x=12$ dai $x=4$ ", Estudante B:"...fiz por substituição e achei $x=4$ tb, e $y=5$, que dá igual ao de vcs....", Estudante B:" legal...fizemos então.....". Este exemplo de matemática é um extrato do trabalho desenvolvido na pesquisa-ação sobre os Espaços de Aprendizagem Digital da Matemática no Facebook em 2012 com os estudantes do $1^{\circ}$ ano do ensino médio integrado em informática.

Os estudantes estão realizando reflexionamentos, sendo que, a cada interação cooperativa, ocorre uma mudança de patamar deste reflexionamento a um nível mais elevado. Além disso, de cada reflexão se constitui uma nova abstração reflexionante, que de um conteúdo viabiliza nova forma, e assim sucessivamente, até se conceber uma abstração refletida, ou seja, uma abstração reflexionante com tomada de consciência.

Desta forma, para cooperar é necessário colaborar, mas existe uma distinção entre a colaboração como forma de aprendizagem e como método de pesquisa qualitativa (Bona et al., 2011). Isto é, a colaboração para Piaget (1973) é uma forma de aprendizagem, enquanto que em muitas pesquisas na área da Informática na Educação a ideia de colaboração é o método de pesquisa qualitativa, como exemplo, a metodologia da pesquisa-ação de Barbier (2002) e Thiolllet (2011) adotada com os Portfólios de Matemática de Bona (2010) e com o Espaço de Aprendizagem Digital de Bona, Basso e Fagundes (2011).

Tal metodologia de pesquisa propõem a colaboração como a reunião de ações de pesquisa do professor/pesquisador com as dos estudantes/pesquisadores, em que ambos têm o mesmo objetivo, aprender a aprender matemática. Nessa perspectiva, além do professor de matemática ser a pessoa que possui o conhecimento da ciência da matemática ele pode conhecer a forma que os estudantes aprendem tal conhecimento utilizando ou se apropriando de NTDs. Assim, tal cooperação leva à realização de aulas mais interessantes e capazes de mobilizar todos os participantes envolvidos.

Segundo Piaget (1998), o papel da cooperação para o desenvolvimento da objetividade é importante. Para ele, a cooperação é necessária para conduzir o sujeito à objetividade, porque, por si só, o sujeito permanece prisioneiro de sua perspectiva particular. Ela é condição do verdadeiro pensamento, pois permite que o sujeito renuncie a seus interesses próprios para pensar em função da realidade social. A capacidade de o sujeito colocar-se do ponto de vista dos outros leva a inteligência a adotar uma atitude própria ao espírito científico, desde suas formas menos complexas, que consiste em dissociar o real das ilusões antropocêntricas. "A objetividade supõe a coordenação das perspectivas e esta implica a cooperação" (Piaget, 1998, p. 142-144).

Conforme Piaget, a cooperação é essencialmente uma fonte de regras para o pensamento. A lógica constitui um conjunto de regras assimiladas pelo sujeito. Essas 
não são inatas, pois, desde o funcionamento inicial da inteligência prática, existe a necessidade de coerência quase orgânica, que predizem a coerência formal do pensamento. Trata-se de uma elaboração de esquemas que se equivalem, no plano da ação, aos conceitos no plano do pensamento formal e, uma construção de relações práticas que perpassam as relações seguintes.

As relações próprias à lógica diferem das relações práticas da inteligência elementar por implicarem normas especificamente sociais, como a reciprocidade. Desta forma, a cooperação age sobre a tomada de consciência do sujeito, sobre seu senso de objetividade e culmina na constituição de toda uma estrutura normativa que completa o funcionamento da inteligência, no sentido da reciprocidade, norma fundamental que conduz ao pensamento formal.

Com base nos estudos piagetianos apresentados, pode-se concluir que a cooperação é o conjunto das interações entre indivíduos que desejam alcançar o mesmo objetivo. Ela conduz a uma crítica mútua e a uma objetividade progressista. Cada indivíduo constitui um sistema próprio de referência e de interpretação, onde a verdade resulta da coordenação entre pontos de vista distintos. Considerar o pensamento do outro significa substituir o egocentrismo do ponto de vista próprio por uma metodologia de interações verdadeiras, o que implica não somente a compreensão recíproca, mas também a constituição da própria razão. Nesta perspectiva, tem-se a lógica das relações como produto da cooperação, conforme Piaget (1998).

O termo egocentrismo foi utilizado por Piaget para designar a incapacidade inicial do sujeito para se descentrar, para modificar a sua perspectiva. Esse termo corresponde à falta de descentração. $\mathrm{O}$ egocentrismo cognitivo provém de uma falta de diferenciação entre o próprio ponto de vista e os outros possíveis, e não do individualismo que determina as relações com outras pessoas. Significa, ao mesmo tempo, ausência de consciência de si e ausência de subjetividade, para Montangerro (1998).

Piaget (1998) afirma que a cooperação é condição sine qua non para conduzir o sujeito à objetividade. As construções de um mundo objetivo dependem das construções do mundo subjetivo. Nesta perspectiva, “(...) só se pode falar na interiorização da cultura se existir anteriormente a interiorização das ações" (Becker, 2005, p. 32).

Cabe destacar que, para Piaget (1973), toda sociedade é um sistema de obrigações (regras), trocas (valores) e de símbolos convencionais que servem de expressão as regras e aos valores (sinais). Toda conduta executada em comum se traduz necessariamente pela elaboração de normas, de valores ou significantes convencionais. Com isso para cooperar é necessário regras autônomas e respeito mutuo entre todos os envolvidos, ou seja, quando os estudantes estão numa rede todos sabem as regras e que todos são importantes para o espaço, assim o mesmo deve ocorrer na sala de aula, seja ela presencial ou virtual, para que o objetivo da aprendizagem seja compreendido por todos os estudantes e professores. 
Destaca-se que no trabalho com os Portfólios de Matemática de Bona (2010), assim como no do Espaço de Aprendizagem Digital da Matemática de Bona et al. (2011a) estão presentes um "contrato didático" entre os estudantes e a professora nas aulas de matemática com direitos e deveres de ambos. Este documento é construído nos primeiros dias de aula do ano e é assinado pelos pais e/ou responsáveis dos estudantes. $\mathrm{Na}$ pesquisa do espaço se faz presente no referido contrato a sala de aula não apenas presencial mas também a sala de aula virtual, ou seja, o espaço de aprendizagem digital da matemática que é um ambiente de sala de aula online, onde os estudantes resolvem problemas de matemática entre si e também com a presença da professora as vezes.

Para ilustrar apresenta-se alguns exemplos de direitos e deveres presentes neste contrato: "a professora pode dar tema toda a semana de forma que a gente possa resolver estes em duplas; a professora preferencialmente deve fazer uso das tecnologias digitais para inserir novas materiais de matemática; os alunos devem tentar com vontade participar das aulas e fazer as atividades mesmo que elas sejam dificeis sem ficar reclamando; os alunos devem atender as duvidas dos colegas online no espaço em 30 horas no máximo; os alunos devem aprender a resolver os problemas de forma explicada para que todos entendam online e como não tem exigência de tempo dá para cada um organizar suas ideias e escrever bem direitinho online...."

Destas duas pesquisas elucidam-se exemplos de aprendizagem de conceitos de matemática inseridos no contexto apresentado neste artigo, porque estas pesquisas se apropriam dos conceitos de rede, ciberespaço e cibercultura como elementos para a definição do Espaço de Aprendizagem Digital da Matemática no que cabe a área da Informática na Educação, e também tem incorporado e adotado pela escolha dos estudantes a aprendizagem cooperativa, que necessita destas conceituações de interação, da própria aprendizagem cooperativa no concepção construtivista de Piaget (1973) e inseridas na cultura digital.

Entende-se que o modelo apontado como questão anteriormente não é único e nem pode ser generalizado, pelo simples processo dinâmico que é a aprendizagem, ainda mais quando está inserida na cultura digital. Mas pode-se apontar suas ideias básicas e essenciais para este modelo como feito anteriormente, em que sob o ponto de vista da aprendizagem, cabe ao professor proporcionar aos estudantes meios para que aprendam de modo a cooperar com todos os colegas.

A teoria de Piaget explica o processo de aprendizagem cooperativa e as NTDs viabilizam a ação dos professores, e através delas é possível proporcionar aos estudantes um aprender a aprender, aprender a pensar por meio de ações cooperativas, segundo Bona et al. (2011a), como constatado nas pesquisas supracitadas na área da matemática com os portfólio e com o espaço de aprendizagem digital. Na primeira pesquisa, mostrou-se que as tecnologias digitais proporcionam um aprender a aprender coletivo entre todos os estudantes, pois cada um coopera, com diferentes ações, até a compreensão das atividades seja feita por todos, inclusive em relação à professora, quando vale-se, por exemplo, de recursos digitais que a mesma desconhece. Já a 


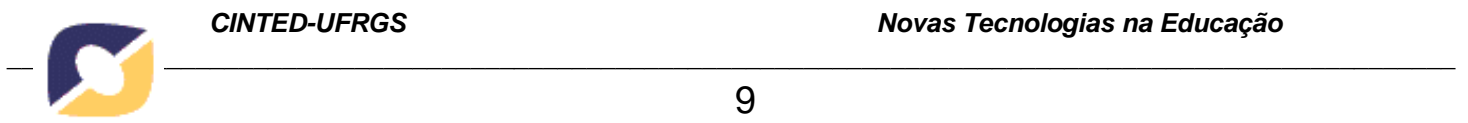

segunda pesquisa vai muito além, porque cria uma definição de espaço de aprendizagem digital da matemática e viabiliza neste a aprendizagem cooperativa com efetivos resultados de construção de conceitos de matemática, exemplificados em Bona, et al. (2011b) e (2011a).

\section{Considerações Finais}

$\mathrm{O}$ artigo cumpre sua finalidade de discutir os conceitos importantes para a área da Informática na Educação como: redes, ciberespaço, cibercultura, interação, aprendizagem cooperativa na cultura digital, além de citar pesquisas que incorporam tais conceituações no processo de aprender a aprender matemática com resultados de efetiva aprendizagem de conceitos de matemática.

Importante este momento de reflexão ao professor/pesquisador lato senso e stricto senso porque a prática e a teoria devem estar conectadas e em processo de integração permanente para que o processo de aprendizagem esteja sempre inserido e incorporado da cultura presente na vida dos estudantes, no caso atual, a cultura digital. E é por meio deste olhar que os pesquisadores da área da Informática na Educação podem se apropriar de problemas reais da escola na sala de aula de matemática, como exemplo do pouco interesse destes estudantes em participar, para desenvolver novas pesquisas que visem melhorar a qualidade da educação brasileira, mesmo que num primeiro momento seja complicado e se enfrente muitas resistências, que é normal do ser humano ter medo da mudança.

Por fim, o "escutar os estudantes" como é feito em ambas as pesquisas citadas na área da matemática proporciona um crescimento profissional do professor de matemática e também uma satisfação enorme de ver os estudantes mobilizados, envolvidos com as atividades de matemática apropriando-se do que lhes é interessante: as tecnologias digitais em rede e a aprendizagem cooperativa. Paralelamente, os estudantes sentem-se satisfeitos por aprender a aprender matemática do seu jeito e fazendo uso da cultura digital que estão inseridos e por meio de interações que estes tem tanta familiaridade.

\section{Referências Bibliográficas}

ARRUDA, E. Ciberprofessor: Novas Tecnologias, Ensino e Trabalho Docente. Belo Horizonte: Autêntica, 2004.

BARBIER, R. A Pesquisa-Ação. Série Pesquisa em Educação. Tradução de Lucie Didio. Brasília: Liber Livro Editora, 2004.

BECKER, F. Coleção memória da pedagogia, n.1: Jean Piaget. Editor Manuel da Costa Pinto; [colaboradores Lino de Macedo...et.]. Rio de Janeiro: Ediouro; São Paulo: Segmento-Duetto, 2005. 


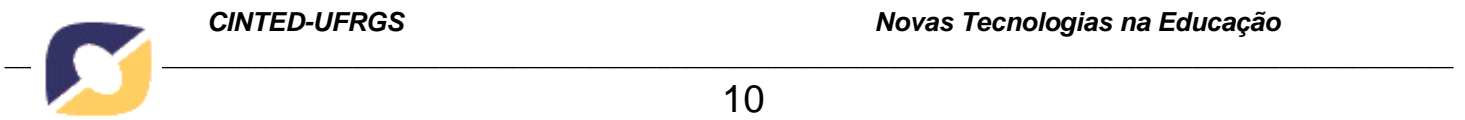

BONA, A. S. D. Portfólio de Matemática: um instrumento de análise do processo de aprendizagem. Dissertação (Mestrado em Ensino de Matemática) - Programa de PósGraduação em Ensino de Matemática. Porto Alegre: UFRGS, 2010.

BONA, A.S.D.; FAGUNDES, L.C; BASSO, M.V.A. A cooperação e/ou a colaboração no Espaço de Aprendizagem Digital da Matemática. In: RENOTE - Revista Novas Tecnologias na Educação, v. 9, n. 2, 2011 a.

BONA, A.S.D.; SCHAFER, P.; FAGUNDES, L.C; BASSO, M.V.A. Cooperação na Complexidade: Possibilidades de Aprendizagem Matemática suportadas por Tecnologias Digitais. In: RENOTE - Revista Novas Tecnologias na Educação, v. 9, n. 2, $2011 b$.

D'AMBRÓSIO, U. Educação para uma sociedade em transição. Campinas, SP: Papirus, 1999.

FAGUNDES, L.C. Informática e o processo de aprendizagem. In: Revista Psicologia: reflexão e crítica, v. 5, n. 1, Porto Alegre: UFRGS, 1993.

KAMII, C. Reinventando a aritmética : implicações da teoria de Piaget. Campinas: Papirus, 1986.

LEMOS, A. Cibercultura: tecnologia e vida social na cultura contemporânea. Porto Alegre: Sulina, 2002; p 116 e 123.

LÉVY, P. Cibercultura. São Paulo: 34, 1999; 17.

MORIN, E. A cabeça bem-feita: repensar a reforma, reformar o pensamento. Rio de Janeiro: Bertrand Brasil, 2000.

PARENTE, A. Tramas da rede: novas dimensões filosóficas estéticas e políticas da comunicação. Organizador: André Parente - Porto Alegre, Sulina, 2004, 91-110.

PIAGET, J. Estudos Sociológicos. Rio de Janeiro: Forense, 1973.

PIAGET, J. Sobre a pedagogia. São Paulo: Casa do Psicólogo, 1998.

THIOLLENT, M. Metodologia da pesquisa-ação. 18ed. São Paulo: Cortez, 2011. 